\title{
Pelatihan Public Speaking Kepemanduan untuk Relawan Museum
}

\author{
Yulianti Fajar Wulandari' ${ }^{1}$, Yan Bastian ${ }^{2}$, Murtiadi ${ }^{3}$, Mike Indarsih ${ }^{4}$ \\ 1,2,3,4Universitas Bina Sarana Informatika \\ email: 1yulianti.yfw@bsi.ac.id, 2yan.ybn @bsi.ac.id, 3murtiadi.mdi @bsi.ac.id, \\ ${ }^{4}$ mike.mih@bsi.ac.id
}

\begin{abstract}
Abstrak
Jakarta merupakan kota dengan destinasi wisata museum terbanyak di Indonesia, yakni sekitar 70 museum. Tema dan pengelolaan museum tersebut bervariasi, mulai dari yang bertema umum kesejarahan kota Jakarta sampai ke tema khusus seperti kehutanan, transportasi, bank dan lain sebagainya. Kepemilikan dan pengelolaannya pun bervariasi, mulai dari milik Pemprov DKI Jakarta sampai milik pribadi. Sehingga tiket masuknya pun bervariasi pula, dari yang gratis sampai yang ratusan ribu rupiah. Permasalahan utama museum-museum di Jakarta adalah kurangnya SDM terutama untuk pelayanan seperti pemandu museum. Ikatan Pemandu Museum Indonesia (IPMI) berupaya mengatasi permasalahan ini dengan menjaring generasi muda milenial untuk menjadi relawan museum. Relawan ini diberi pelatihan teknik berbicara didepan umum (public speaking) dengan materi seputar kepemanduan di museum. Pelatihan ini bertujuan untuk pertama, menjaring generasi muda milenial untuk menjadi relawan museum sebagai pemandu; kedua membekali relawam museum dengan keterampilan public speaking kepemanduan untuk bergiat di museum; ketiga untuk mengatasi masalah atas kurangnya tenaga pelayanan khususnya pemandu museum. Keterampilan kepemanduan di museum ini juga bermanfaat bagi para relawan dalam menambah pengetahuan dan pengalaman yang mungkin berguna untuk bekerja di bidang kepariwisataan khususnya kepemanduan di museum.
\end{abstract}

Kata Kunci: Kepemanduan, Relawan, Museum, Public Speaking

\begin{abstract}
Jakarta city is one of the cities which have lots of museums as tourist destinations in Indonesia. The amount of it is around 70 museums. The theme and management of the museum varies, ranging from the general theme of the historical city of Jakarta to special themes such as forestry, transportation, banks and so on. Ownership and management also varies, starting from the DKI Jakarta Provincial Government to private property. So the entry ticket also varies, from free to hundreds of thousands of rupiah. DKI Jakarta Provincial Government has included the museum as one of the mainstay tourist destinations for local and foreign tourists. The shortage of service personnel, especially guides, is the main problem facing these museums. The Indonesian Museum Guides Association (IPMI) seeks to overcome this problem by recruiting millennial young people to become museum volunteers. These volunteers were given training in public speaking techniques with material about tour guide in the museum. The training aims are, firstly, gaining millennial youths to become museum volunteers as guides; secondly, equips museum volunteers with guiding public speaking skills to work at the museum; third, to overcome the problem of lack of service personnel, especially
\end{abstract}


museum guides. The guiding skills in the museum are also useful for volunteers in adding knowledge and experience that might be useful for working in the field of tourism, especially guiding in the museum.

Keywords: Guide, Volunteers, Museum, Public Speaking

\section{Pendahuluan}

\section{Latar Belakang}

Kegiatan Pengabdian Masyarakat yang dilakukan oleh Tim Dosen Fakultas Komunikasi dan Bahasa, Universitas Bina Sarana Informatika, Jakarta, adalah bagian dari kewajiban Tri Dharma Perguruan Tinggi yang diatur oleh Undang-Undang Nomor 20 Tahun 2003 tentang Sistem Pendidikan Nasional. Dalam peraturan ini disebutkan bahwa Perguruan Tinggi berkewajiban menyelenggarakan Pendidikan, Penelitian dan Pengabdian kepada Masyarakat. Pengabdian masyarakat kali ini menggandeng Ikatan Pemandu Museum Indonesia (IPMI) sebagai mitra.

Adapun, propinsi DKI Jakarta memiliki lebih dari 70 museum dan merupakan propinsi dengan jumlah museum terbanyak di Indonesia. Museum-museum tersebut dimiliki dan dikelola antara lain oleh Pemprov DKI Jakarta, Kementeriankementerian, BUMN/BUMD, Swasta (Yayasan) dan/atau Perorangan (Pribadi). Dinas Pariwisata dan Kebudayaan DKI Jakarta telah menjadikan museum sebagai salah satu destinasi wisata edukasi dan rekreasi bagi wisatawan lokal maupun turis mancanegara.

Permasalahan yang dihadapi museum-museum di Jakarta, umumnya adalah kekurangan sumberdaya manusia yang profesional, terutama personil untuk melayani pengunjung, yakni dalam hal pelayanan pemanduan. Dalam wawancaranya, Amat Kusaeni Al Alexs, Ketua Umum Ikatan Pemandu Museum Indonesia (IPMI) menyatakan banyak pengelola museum yang mengeluhkan kekurangan tenaga pelayanan seperti pemandu, sementara di sisi lain banyak pelajar dari SMK jurusan Kepariwisataan membutuhkan pengalaman bekerja atau tempat magang di museum untuk mempersiapkan mereka di dunia kerja. "IPMI berusaha menjembatani keduanya, mempertemukan pihak yang kekurangan SDM yakni museum dengan para pelajar yang ingin menjadi relawan di museum" (dalam wawancara di tahun 2019).

IPMI yang merupakan salah satu organisasi non pemerintah atau lembaga swadaya masyarakat yang berupa perkumpulan profesi pemandu museum berupaya melakukan seuatu yang positif untuk membantu permasalahan museum tersebut. Brad Kenney (Wulandari, 2019) mendefinisikan lembaga swadaya masyarakat adalah sebuah organisasi nirlaba yang eksis di luar kendali pemerintah, bisnis, partai politik atau kelompok bersenjata. Mereka bisa berentang dari organisasi global yang sangat terstruktur sampai aktivis lokal yang ikatannya longgar. Sumber dana mereka dari iuran keanggotaan atau bantuan lembaga internasional atau pemerintah. 
Betts (Wulandari, 2019) menjelaskan wujud lembaga swadaya masyarakat dapat berupa yayasan filantropis, asosiasi kepentingan khusus, koperasi, lembaga pelatihan dan penelitian, ikatan perkumpulan, organisasi kewanitaan dan lain sebagainya, yang menjembatani aspirasi anggotanya dengan pemerintah. Aktivitasnya meliputi pendidikan, pelatihan. pembangunan masyarakat, penerbitan, promosi, koperasi, penelitian dan pengembangan, pembentukan modal, teknologi tepat guna, bantuan hukum, keluarga berencana, program kesehatan, perlindungan konsumen, transmigrasi, perlindungan lingkungan hidup dan berbagai proyek yang meningkatkan pendapatan dan kesejahteraan masyarakat (Wulandari, 2019).

IPMI dalam hal ini berperan sebagai mitra pelatihan dan penelitian yang berinisiatif mengumpulkan masyarakat umum, terutama generasi muda milenial untuk berpartisipasi menjadi relawan yang dapat melakukan kerja sosial kepemanduan museum di Jakarta. Oleh karena itu Tim Akademisi dari Fakultas Komunikasi dan Bahasa, Universitas Bina Sarana Informatika melalui Program Studi Ilmu Komunikasi bekerjasana dengan IPMI untuk membekali para calon relawan museum tersebut dengan pengetahuan melalui pelatihan public speaking kepemanduan museum, yang meliputi materi seputar pengenalan museum, etika pemandu, teknik berbicara di depan umum dan lain sebagainya.

\section{Profil Mitra Ikatan Pemandu Museum Indonesia (IPMI)}

Ikatan Pemandu Museum Indonesia (IPMI) adalah sebuah organisasi profesi yang menaungi para Pemandu Museum di seluruh Indonesia. Gagasan pembentukan IPMI telah digaungkan sejak 2015, sejalan dengan upaya sertifikasi para anggotanya dan calon pengurus agar terbentuk ikatan profesi pemandu museum di Indonesia yang profesional dan tersertifikasi. Dengan demikian, SDM di bidang kepariwisataan khususnya Pemandu Museum, menpunyai keahlian dan mampu menghadapi kompetensi di era Masyarakat Ekonomi Asia (MEA) yang mulai diberlakukan pada tahun 2020 ini.

IPMI telah tercatat sebagai perkumpulan profesi berdasarkan Surat Keputusan Menteri Hukum dan HAM No.AHU-0000894.AH.01.07 Tahun 2019 tentang Pengesahan Pendirian Badan Hukum Perkumpulan Pemandu Museum Indonesia, disingkat IPMI, dengan Nomor Akte Notaris 2525 tertanggal 25 Januari 2019. Kantor Sekretariat IPMI berada di Museum Sejarah Jakarta, Jalan Taman Fatahilah No.1, Kawasan Kota Tua, Jakarta Barat. Ketua Umum IPMI periode 2019 - 2023 adalah Amat Kusaini Al Alexs, yang juga merupakan Koordinator Tourguide di Museum Sejarah Jakarta, sedangkan Wakil Ketuanya adalah Dhanu Wibowo dari Museum Kebangkitan Nasional.

IPMI sebagai wadah organisasi profesi selalu mengedukasi para pengelola museum, khususnya para pemandu untuk menjadi profesional dalam pekerjaannya, antara lain dengan menyelenggarakan sertifikasi pemandu museum yang bekerjasama dengan LSP Pramindo dan Dinas Pariwisata dan Kebudayaan Provinsi DKI Jakarta. Sertifikasi pemandu ini telah dilakukan sejak IPMI masih dalam embrio di tahun 
2015. Anggota IPMI yang terdaftar saat ini lebih dari seratus pemandu museum yang telah mengantongi sertifikat kompetensi pemandu museum di Indonesia.

Kegiatan IPMI lainnya adalah menyelenggarakan pelatihan-pelatihan baik bersifat kerjasama, berbayar maupun sosial dengan beberapa lembaga. Pelatihan tersebut antara lain mengenai Manajemen Museum, Pelayanan Prima maupun Kepemanduan Museum. Dalam kegiatan sosialnya, IPMI menjaring calon relawan museum yang berasal dari generasi muda milenial, yakni para pelajar dan mahasiswa dengan rentang usia 15 sampai 25 tahun untuk diberikan pelatihan public speaking khususnya kepemanduan bagi para generasi muda milenial yang ingin menjadi relawan di museum.

\section{Perumusan Masalah}

Masalah yang dihadapi oleh museum-museum di DKI Jakarta adalah:

a. Kurangnya tenaga pemandu museum untuk melakukan pelayanan pemanduan

b. Perlunya pelatihan public speaking kepemanduan bagi generasi muda milenial yang berminat menjadi relawan museum

\section{Tujuan Kegiatan}

a. Pelatihan ini bertujuan untuk menjaring generasi muda milenial untuk menjadi relawan museum di bidang pemanduan

b. Membekali para calon relawan museum dengan pengetahuan tentang teknik berbicara di depan umum

c. Memberikan pengetahuan tentang permuseuman dan etika kepemanduan di museum

d. Melatih dengan mempraktekan pemanduan di museum secara langsung.

\section{Manfaat Kegiatan}

a. Pelatihan ini bermanfaat bagi museum dengan adanya relawan museum yang siap melayani dengan pengetahuan yang baik melalui pelatihan

b. Para relawan mendapatkan pengetahuan tentang dunia permuseuman.

c. Para relawan mendapatkan pelatihan tentang teknik berbicara di depan umum dan kepemanduan di museum

d. Para relawan mendapatkan pengalaman dalam bekerja social sehingga memperkaya diri yang berguna untuk bekal di masa depan khususnya dunia kerja.

\section{Metode}

Pelatihan public speaking kepemanduan bagi relawan museum dirancang sedemikian rupa melalui pemaparan atau proses pembelajaran teori dan pembelajaran praktek kepemanduan secara langsung. Menurut Nuryati (Gata, 2020), pendekatan kedua pembelajaran tersebut dapat memberikan pemahaman secara komprehensi terkait materi yang disampaikan dan dapat diimplementasikan secara aplikatif dalam dunia kerja. Metode pelatihan secara teori meliputi ceramah, tanya jawab dan diskusi, 
sedangkan secara praktek dilakukan melalui simulasi. Kegiatan pelatihan ini terbagi atas lima sesi, yakni:

1. Sesi ceramah dengan materi pemahaman museum dan kepemanduan yang disampaikan oleh Wakil Ketua IPMI sekaligus Edukator dari Museum Kebangkitan Nasional, yakni Bapak Dhanu Wibowo.

2. Sesi ceramah dengan materi teknik kepemanduan (public speaking) di museum yang disampaikan oleh Dosen Prodi Ilmu Komunikasi, Fakultas Komunikasi dan Bahasa, Universitas Bina Sarana Informatika, yakni Ibu Yulianti Fajar Wulandari.

3. Sesi ceramah dengan materi trik kepemanduan untuk pelayanan maksimal dan prima yang dipaparkan oleh Ketua IPMI sekaligus Koordinator Tourguide Museum Kesejarahan Jakarta yakni Bapak Amat Kusaeni Al Alexs.

4. Sesi tanya jawab dan diskusi yang dipandu oleh mahasiswa yang terlibat dalam kegiatan pengabdian masyarakat yakni Audri Rizkani

5. Sesi praktikum, dimana para peserta dibagi dalam tiga kelompok dan diminta mempraktekkan teknik-teknik yang telah dipelajari dengan arahan, Kelompok 1 oleh Bapak Murtiadi; Kelompok 2 oleh Bapak Yan Bastian dan Kelompok 3 oleh Ibu Mike Indarsih, Dosen Fakultas Komunikasi dan Bahasa, Universitas Bina Sarana Informatika.

6. Perlombaan juga diadakan untuk menyemangati peserta agar mampu mempraktekkan kemampuan public speaking kepemanduan museum dengan sebaik-baiknya, karena peserta yang mendapat nilai tertinggi akan diberikan hadiah, dengan dipandu oleh mahasiswa, Nurwahyu Ramadhani.

\section{Hasil dan Pembahasan}

Kegiatan Pengabdian Masyarakat yang dilakukan oleh Dosen dan Mahasiswa Fakultas Komunikasi dan Bahasa, Universitas Bina Sarana Informatika, Jakarta, dengan mitra kegiatan yakni Ikatan Pemandu Museum Indonesia (IPMI). Lokasi pengabdian masyarakat bertempat di Aula Museum Kebangkitan Nasional, Jalan Abdul Rachman Saleh No 26, Jakarta Pusat. Pelatihan diadakan selama dua hari, yakni Sabtu dan Minggu. Jumlah peserta dibatasi hanya 20 peserta setiap harinya. Syarat peserta adalah berusia 15 sampai dengan 25 tahun, dan mempunyai minat untuk menjadi relawan di museum.

Tahap pertama pelaksanaan kegiatan diawali dengan pemaparan teori tentang pemahaman museum dan kepemanduan. Definisi museum menurut International Council of Museum (ICOM) adalah lembaga yang mempunyai fungsi sebagai tempat menyimpan, merawat dan memamerkan benda dan atau koleksi bersejarah; sebagai tempat rekreasi (wisata); dan sebagai tempat untuk informasi dan media pendidikan. Jenis museum menurut PP No. 66 Tahun 2015 tentang Museum, terbagi atas dua jenis yakni museum umum dan museum khusus. Dimana museum umum adalah museum yang menyimpan benda koleksi yang bersejarah secara umum atau menyeluruh, dan biasanya dikelola oleh Pemerintah Pusat dan atau Pemerintah Daerah. Museum khusus adalah museum mengkoleksi benda-benda dengan tema tertentu (khusus). 
Pengelolaan museum biasanya melibatkan pemandu dalam hal pelayanan, maka dapat dikatakan bahwa pemandu adalah ujung tombak pelayanan. Pemandu terbagi atas dua jenis, yakni Pemandu Wisata Umum dan Pemandu Wisata Museum. Dalam kepemanduan, terbagi empat tingkatan kepemanduan yakni: Pemandu Khusus Museum; Pemandu Pramuwisata Muda; Pemandu Pramuwisata Madya dan Pimpinan Perjalanan (tourleader). Dalam Masyarakat Ekonomi Asia (MEA) yang mulai diberlakukan tahun 2020 ini, profesi pemandu akan bersaing ketat dengan para tenaga kerja asing yang sejenis. Untuk mengantisipasi hal tersebut, Indonesia telah memiliki Lembaga Sertifikasi Profesi (LSP); Badan Nasional Sertifikasi Profesi (BNSP) yang berhak melakukan sertifikasi kompetensi.

Sesi kedua pelatihan ini adalah ceramah tentang etika kepemanduan. Penampilan dan cara berinteraksi dengan publik atau pengunjung yang dilayani secara verbal maupun nonverbal (simbol-simbol) adalah bagian dari paparan ceramah ini. Interaksionisme simbolis adalah sebuah pergerakan dalam sosiologi, berfokus pada cara-cara manusia membentuk makna dan susunan dalam masyarakat melalui percakapan. Dalam bentuknya yang paling mendasar, sebuah tindak sosial melibatkan sebuah hubungan dari tiga bagian, yakni gerak awal tubuh dari salah satu individu, respon dari orang lain terhadap gerak tubuh tersebut, dan sebuah hasil. Hasilnya adalah arti tindakan tersebut bagi pelaku komunikasi (Littlejohn \& Foss, 2009).

Makna merupakan sebuah hasil komunikasi yang penting. Pemaknaan anda merupakan hasil dari interaksi dengan orang lain. Gerak tubuh adalah salah satu simbol signifikan terkait makna. Masyarakat ada karena karena adanya simbolsimbol signifikan. Artinya, kita dapat mendengar diri kita sendiri dan meresponnya seperti orang lain lakukan kepada kita karena adanya kemampuan untuk menyuarakan simbol. Oleh karena itu, masyarakat terdiri atas sebuah jaringan interaksi social dimana anggota-anggotanya menempatkan makna bagi tindakan mereka dan tindakan orang lain dengan menggunakan simbol-simbol (Littlejohn \& Foss, 2009).

Citra diri bersifat universal, tiap orang berusaha mendefinisikan diri melalui komunikasi. Maka, komunikasi yang bertujuan membangun citra diri, sangat berbeda pada setiap orang dan pada setiap budaya. Setiap budaya memiliki caracara berperilaku yang terkait citra diri yang bersifat preventif dan restoratif. Perilaku komunikasi preventif ditujukan untuk melindungi diri bila merasa terancam akan citra diri atau citra kelompoknya. Sedangkan perilaku komunikasi restoratif ditujukan untuk membangun kembali citra diri setelah mengalami kehilangan harga diri. Maka, hal-hal yang terkait etika kepemanduan museum untuk membangun citra diri yang baik seorang pemandu museum pun dipaparkan sebagai berikut:

a. Rapi dan menarik dalam berpakaian (memakai sepatu, kemeja, dan menggunakan ID Card serta tidak memakai topi dan penutup wajah)

b. Fokus pada pelayanan yang ramah, penuh senyum dan tidak menggunakan atau menelpon saat bertugas 
c. Sopan dalam berbicara, yakni tidak berbicara kasar, berbicara sesuai kebutuhan, humoris dan mampu menjawab pertanyaan dengan baik)

d. Sopan dalam berperilaku, disesuaikan dengan adat dan budaya kesopanan yang berlaku.

Etika kepemanduan sendiri erat kaitannya dengan bentuk-bentuk komunikasi verbal dan nonverbal. Menurut Burgoon (Morrisan, 2013), makna yang dibawa oleh bentukbentuk verbal dan nonverbal adalah terikat dengan konteks, atau sebagian ditentukan oleh situasi dimana bentuk-bentuk komunikasi verbal dan nonverbal dihasilkan. Baik bahasa dan bentuk-bentuk nonverbal memungkinkan komunikator untuk menggabungkan sejumlah kecil tanda ke dalam berbagai ekspresi atau ungkapan makna yang kompleks tanpa batas. Sistem tanda nonverbal sering dikelompokkan menurut tipe aktifitas atau kegiatan yang digunakan di dalam tanda tersebut yang menurut Burgoon sendiri terdiri atas tujuh tipe, yaitu bahasa tubuh (kinesics), suara (vocalic atau paralanguage), tampilan fisik, sentuhan (haptics) ruang (proxemics), waktu (chronemics) dan objek.

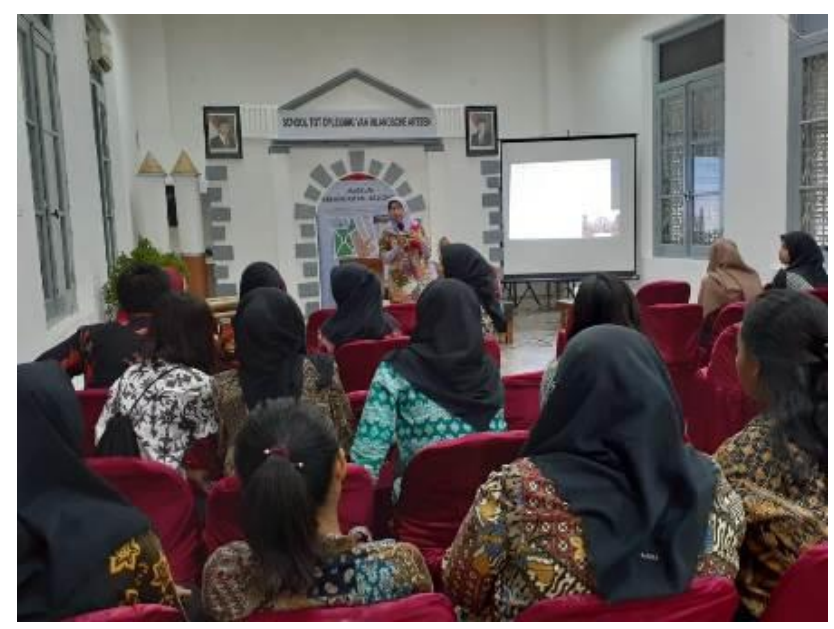

Gambar.1 Ceramah pemahaman museum dan etika kepemanduan

Sesi ketiga kembali diisi dengan ceramah mengenai teknik kepemanduan. Peserta diberi pengetahuan mengenai:

1. Teknik Kepemanduan yang meliputi greeting, welcoming, introducing, telling museum story, inform museum artifacts, answering question, closing.

2. Touring Tata Pamer Museum, antara lain mengikuti alur cerita (story line), menjelaskan tata tertib kunjungan, menceritakan koleksi, mengatur waktu kunjungan dan menghidupkan suasana yang akrab dengan humor.

3. Sikap dalam Memandu, yakni tegas dan luwes, terampil, cekatan, teliti dan tanggap dalam pelayanan.

Trik kepemanduan untuk pelayanan maksimal dan prima menjadi sesi terakhir paparan ceramah teori. Peserta dibekali tips dan trik yang dapat dilakukan untuk melayani pengunjung museum agar puas dan memiliki keinginan untuk dating kembali dan atau merekomendasikannya kepada kerabat maupun sahabat untuk berwisata ke museum. Bahasan tentang hal ini meliputi pengetahuan tentang asal pengunjung, gaya pengunjung, tujuan pengunjung, klasifikasi pengunjung, 
kemampuan pengunjung, pelayanan maksimal dan prima baik untuk pengunjung umum maupun yang berkebutuhan khusus.

Pada sesi akhir, peserta diminta untuk mempraktekkan secara langsung bagaimana memandu dan menjawab pertanyaan pengunjung dengan baik. Di Museum Kebangkitan Nasional atau yang dikenal sebagai Gedung STOVIA, para peserta diminta mempelajari tentang sejarah gedung STOVIA tersebut dan memilih salah satu benda koleksi yang akan dijelaskan kepada pengunjung. Peserta yang lain akan berperan sebagai pengunjung, sedangkan Tutor akan berperan sebagai pengunjung yang bertanya tentan museum maupun koleksinya. Pengamatan di lapangan oleh Tutor menjadi dasar penilaian bagi peserta terbaik yang akan diberi hadiah. Pada penutupan kegiatan, para peserta yang rata-rata adalah pelajar SMK jurusan kepariwisataan, diberikan sertifikat kegiatan pelatihan oleh mitra pengabdian masyarakat, yakni Ikatan Pemandu Museum Indonesia (IPMI).

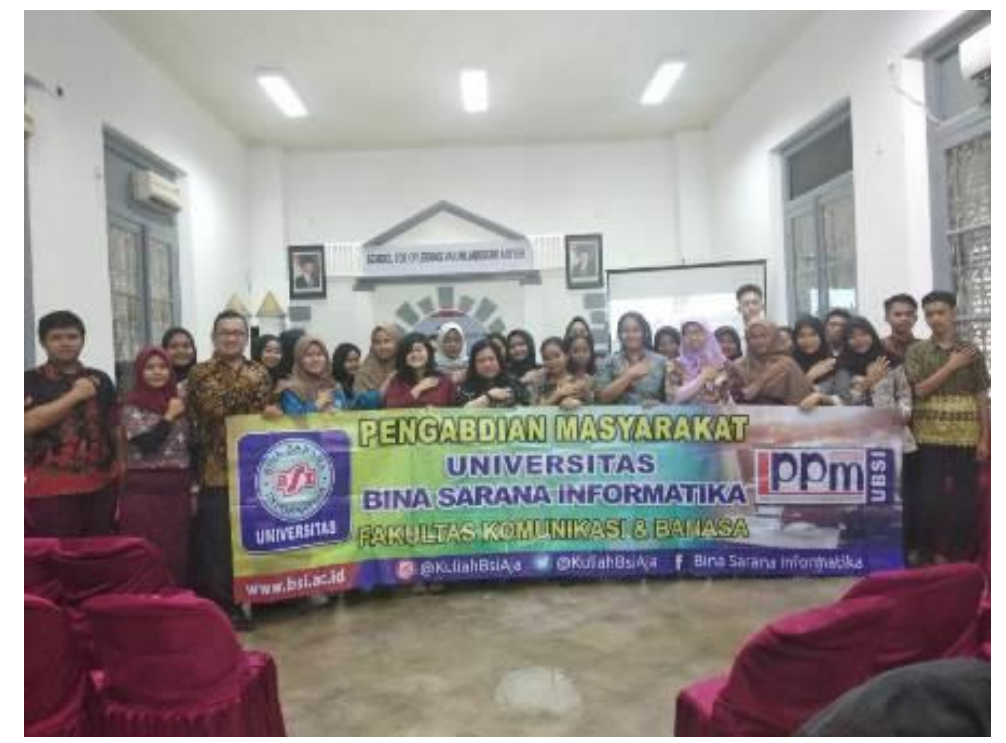

Gambar 2. Penutupan kegiatan pengabdian masyarakat di Museum Kebangkitan Nasional

Setelah kegiatan pelatihan berakhir, Tim Dosen UBSI dan Pengurus IPMI melakukan evaluasi kegiatan. Menurut Sendy Triwilopo (Widjajanto (ed.), 2013), “Evaluasi pada dasarnya adalah menilai sejauh mana pencapaian hasil yang diperoleh (performance outcome). Untuk keperluan dimaksud maka diperlukan berbagai analisa yang menyertainya, yakni: (1) analisis khalayak; (2) analisis media; (3) analisis pencapaian obyektif; (4) analisis kinerja tim dan sumberdaya; (5) analisis pembiayaan".

Sedangkan Dean Kazoleas (Widjajanto (ed.), 2013), menyebutkan ada beberapa bentuk evaluasi, yakni evaluasi formatif, evaluasi menengah, dan evaluasi sumatif, Evaluasi formatif dilakukan sebelum kegiatan dimulai; mencakup rancangan penelitian pendahuluan yang dimaksudkan untuk pemetaan masalah. Evaluasi menengah dilakukan saat pelaksanaan, mulai dari perencanaan hingga tahapantahapan yang dilakukan untuk mengukur dan menguji seberapa efektif pesan diterima saat kegiatan dilakukan; Evaluasi sumatif merupakan langkah akhir dalam kegiatan komunikasi, dimana terlihat efek dari kegiatan yang dijalankan, apakah 
tujuan tercapai? Apakah ada efek yang tidak diinginkan? Mengapa ada tujuan yang belum tercapai?

Evaluasi dilakukan melalui pengamatan di lapangan dan wawancara dengan beberapa peserta terkait kesan yang dirasakan dan pesan yang akan disampaikan sebagai kritik dan saran kepada panitia kegiatan. Respon para peserta umumnya positif dan mereka sangat senang mendapatkan pengetahuan baru tentang permuseuman dan pelayanan sebagai pemandu yang profesional, dan tentunya bermanfaat untuk diterapkan dalam kerja social sebagai relawan museum, maupun di dunia kerja nantinya.

\section{Simpulan dan Rekomendasi}

Pelatihan public speaking kepemanduan bagi relawan museum memberikan solusi bagi masalah kekurangan personil pemandu museum, dimana museum dapat menggunakan relawan museum yang telah dikoordinir oleh Ikatan pemandu Museum Indonesia (IPMI) dan dibekali pengetahuan secara teori dan simulasi praktek oleh Tim Dosen UBSI. Ketua Umum IPMI, Amat Kusaeni Al Alexs sangat antusias dengan kegiatan ini dan tentunya berharap Tim Dosen UBSI melakukan kegiatan pelatihan seperti ini lagi dengan materi-materi yang tidak kalah menariknya untuk memajukan dunia permuseuman di Indonesia, khususnya DKI Jakarta.

\section{Ucapan Terima Kasih}

Kegiatan Pengabdian Masyarakat di Aula Museum Kebangkitan Nasional terselenggara tidak lepas dari kontribusi berbagai pihak, maka penulis mengucapkan terima kasih kepada Bapak Amat Kusaeni Al Alexs, Ketua Umum IPMI selaku mitra kegiatan, Bapak Dhanu Wibowo dan Kepala Museum Kebangkitan Nasional, Bapak Mardi Thesianto atas perkenan tempat lokasi penyelenggaraan kegiatan, juga para narasumber, tutor dan Prodi Ilmu Komunikasi, Fakultas Komunikasi dan Bahasa, Universitas Bina Sarana Informatika, Jakarta, serta parapihak yang tidak dapat disebutkan satu persatu yang telah membantu kesuksesan penyelenggaraan pengabdian masyarakat "Pelatihan Public Speaking Kepemanduan Bagi Relawan Museum".

\section{Daftar Pustaka}

Gatta, Grace; Imelda; Yuliazmi; Siswanto. (2020). Pelatihan Pengelolaan Blog untuk Remaja di RPTRA Manunggal Kelurahan Petukangan Selatan. Jurnal ABDIMAS BSI, Vol.3 No.1, Februari, 39-44.

Kemenko PMK. (2018). MUGALEMON, Museum - Galeri - Monumen Jakarta.

Littlejohn, Stephen W; Foss, Karen A. (2009). Teori Komunikasi. Jakarta: Salemba Humanika.

Meliala, Robbikal Muntaha; Syahril, Romi; Shinta, Martina Rahmi. (2019). Pelatihan Dasar Jurnalistik sebagai Citizen Journalist bagi Remaja Asuhan Ar Ridho. Jurnal SOLMA, Vol.8 No.2, 295-306. 
Morissan. (2013). Teori Komunikasi: Individu Hingga Massa. Jakarta: Kencana Prenada Media Group.

Indonesia. (2015). Peraturan Pemerintah Republik Indonesia Nomor 66 Tahun 2015 Tentang Museum.

Widjajanto, Kenmada (Ed.). (2013). Perencanaan Komunikasi: Konsep dan Aplikasi. Bandung: Ultimus.

Wulandari, Yulianti Fajar; Gusfa, Henny. (2019). Pemberdayaan Komunikasi Lingkungan Hidup WALHI pada PILEG 2014. Jurnal Ilmu Komunikasi Andalan (JIKA), Vol.2 No.2, Juli-Desember, 13-31. 